\title{
Has aidi injection the attenuation and synergistic efficacy to gemcitabine and cisplatin in non-small cell lung cancer? A meta- analysis of 36 randomized controlled trials
}

\author{
Zheng Xiao ${ }^{1,2}$, Chengqiong Wang ${ }^{1,2}$, Ling Chen ${ }^{1,2}$, Xuemei Tang ${ }^{7}$, Lianhong Li ${ }^{7}$, Nana \\ $\mathbf{L i}^{1,2}$, Jing Li, ${ }^{1,5}$, Qihai Gong ${ }^{3}$, Fushan Tang ${ }^{3}$, Jihong Feng ${ }^{4}$, Xiaofei Li ${ }^{6}$ \\ ${ }^{1}$ Evidence-Based Medicine Center, MOE Virtual Research Center of Evidence-based Medicine at Zunyi Medical College, \\ Affiliated Hospital of Zunyi Medical College, Zunyi 563003, Guizhou, China \\ ${ }^{2}$ Department of Respiratory Medicine (Center for Evidence-Based and Translational Medicine of Major Infectious Diseases), \\ Affiliated Hospital of Zunyi Medical College, Zunyi 563003, Guizhou, China \\ ${ }^{3}$ School of pharmacy, Zunyi Medical College, Zunyi 563003, Guizhou, China \\ ${ }^{4}$ Department of Oncology, Affiliated Hospital of Zunyi Medical College, Zunyi 563000, Guizhou, China \\ ${ }^{5}$ Department of Neurology, First People's Hospital of Zunyi City and Third Affiliated Hospital of Zunyi Medical College, Zunyi \\ 563002, Guizhou, China \\ ${ }^{6}$ Department of Parasites, Zunyi Medical College, Zunyi 563003, Guizhou, China \\ ${ }^{7}$ Grade 2012 students, Department of Public Health, Zunyi Medical College. Zunyi 563002, Guizhou, China \\ Correspondence to: Zheng Xiao, email: zy426f@163.com \\ Keywords: aidi injection, non-small cell lung cancer (NSCLC), gemcitabine and cisplatin (GP), randomized controlled trial, meta- \\ analysis
}

Received: July 27, 2016

Accepted: November 07, 2016

Published: November 25, 2016

\section{ABSTRACT}

Gemcitabine and cisplatin is the first line chemotherapy for non-small cell lung cancer with high toxicity. Aidi injection is a cantharidin and astragalu-based Chinese herbs injection in China. Has Aidi injection attenuation and synergistic efficacy to GP in NSCLC? There is lack of strong evidence to prove it. To further reveal it, we systematically evaluated all related studies. We collected all studies about Aidi injection plus GP for NSCLC in Medline, Embase, Web of Science, CNKI, VIP, Wanfang Database, CBM, CCRCT, Chi-CTR, and US-clinical trials (established to June 2015). We evaluated their quality according to the Cochrane evaluation handbook of randomized controlled trials (5.1.0), extracted data following the PICO principles and synthesized the data by Meta analysis. Thirty six RCTs with 2582 NSCLC patients were included, with general methodological quality in most trials. The RR values and their $95 \% \mathrm{CI}$ of Meta-analysis for ORR, DCR and QOL were as following: $1.28(1.17,1.39), 1.11(1.07$, $1.15)$ and $1.81(1.61,2.03)$. The merged RD values and their $95 \% \mathrm{CI}$ of Meta-analysis for myelosuppression, neutropenia, thrombocytopenia, neurotoxicity and nausea and vomiting were as following: $-0.23(-0.29,-0.17),-0.17(-0.22,-0.11),-0.13(-0.18$, $-0.08),-0.06(-0.17,0.05)$ and $-0.15(-0.21,-0.10)$. To compare with GP alone, all differences were statistically significant. The available evidence indicates that Aidi injection plus GP can significantly increase the clinical efficacy and improve the QOL of patients with NSCLC. Aidi injection can reduce myelosuppression, neutropenia, thrombocytopenia neurotoxicity and nausea/vomiting. These indirectly reveal that Aidi injection has the attenuation and synergistic efficacy to GP chemotherapy in NSCLC.

\section{INTRODUCTION}

Lung cancer continues to be a major global health problem, which is diagnosed in more than 1.6 million new patients each year [1]. Approximately $80 \%$ of lung cancers are non-small cell lung cancer (NSCLC) and over $50 \%$ of patients with NSCLC have advanced local invasion and distant metastasis [2]. Hence, they 
are forced to accept chemotherapy, radiotherapy or immunotherapy because losing the chance of surgery [3-4]. Gemcitabine and cisplatin (GP) is the first line chemotherapy and it can increase the overall response rate $(O R R)$ of NSCLC patients [5-7]. But its clinical efficacy is often limited by the acute or subacute toxicity including leucopenia, anemia and thrombocytopenia, et.al [8-9]. All these lead to poor clinical efficacy and substandard quality of life for patients (QOL). Therefore, finding ways to alleviate the toxicity and improve the clinical efficacy and quality of life for patients becomes a key issue.

Aidi injection (Z52020236, China Food and Drug Administration) is a cantharidin and astragalubased Chinese herbs injection in China. It is composed by the extracts of Cantharidin, Astragalus, senticosus Eleutherococcus and Ginseng. They are important anticancer Chinese medicinal herbs which appear to have anti-tumor activity, reduce the acute or subacute toxicity and up-regulate the tumor immunity [10-13]. Can Aidi injection alleviate the toxicity induced by GP chemotherapy in NSCLC? Has it attenuation and synergistic efficacy to GP in NSCLC? Related studies [1416] had shown that Aidi injection plus GP might improve the clinical efficacy and Aidi injection might alleviate the toxicity in NSCLC. Unfortunately, these conclusions were different in different studies with lower sample size. There is lack of strong evidence to prove it. To further reveal whether Aidi injection has attenuation and synergistic efficacy to GP in NSCLC, we systematically evaluated all related studies.

\section{RESULTS}

\section{Search results}

The initial database search identified 1730 published studies using our search strategies, and unpublished studies were not retrieved (Figure 1). After successively applying the study exclusion criteria, 36 RCTs were included.

\section{Characteristics of the included studies}

Thirty six RCTs with 2582 NSCLC patients in China were included in this meta-analysis (Table 1). The cases of Aidi injection plus GP and GP were 1319 and 1263 respectively. The male and female were 1606 and 906 respectively with age range between 21 and 86 years. The dosage of Aidi injection was 50-100ml/day and treatment time was 2-3 weeks and 2-3 cycles by intravenous injection. Clinical efficacy was evaluated by ORR, DCR and QOL. Drug toxicity was evaluated by hematotoxicity, liver injury, renal injury, neurotoxicity and nausea/vomiting.

\section{Methodological bias of the included studies}

In 36 trials, the methods of random allocation were described clearly in only 4 trials. This indicated that there was selectivity bias in the included-studies. The random allocation concealment was open by hospitalization orders respectively in two trials. Not

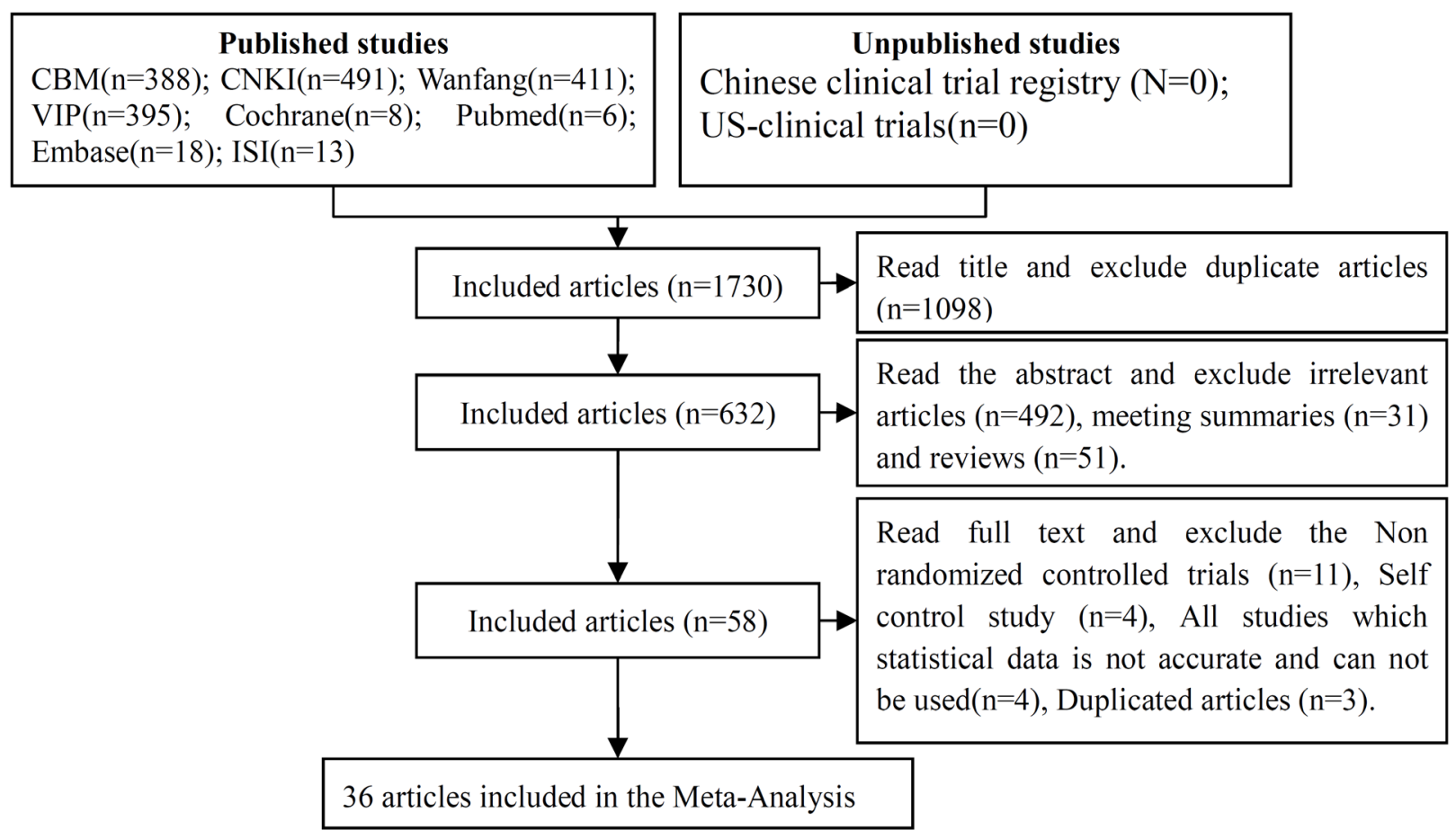

Figure 1: Articles retrieved and assessed for eligibility. 
Table 1: Characteristics of the included studies

\begin{tabular}{|c|c|c|c|c|c|c|c|c|}
\hline \multirow[b]{2}{*}{ First author. Year } & \multicolumn{3}{|c|}{ Patients(III-IV) } & \multicolumn{2}{|c|}{ Interventions } & \multicolumn{3}{|c|}{ Outcomes } \\
\hline & $\mathrm{E} / \mathrm{C}$ & $\mathbf{M} / \mathbf{F}$ & Age & $\begin{array}{c}\text { AD \&GP } \\
(\mathrm{D} / \mathrm{T} / \mathrm{C})\end{array}$ & $\mathbf{C}$ & 01 & $\mathbf{O 2}$ & $\mathbf{O 3}$ \\
\hline Zou, Y.et al2006 [17] & $42 / 39$ & $56 / 25$ & $35-73$ & $80 \mathrm{ml} / 14 \mathrm{~d} / 2-4$ & GP & $\sqrt{ }$ & $\sqrt{ }$ & $\sqrt{ }$ \\
\hline Feng, X, et.al 2008 [18] & $68 / 62$ & $88 / 42$ & $38-74$ & $50 \mathrm{ml} / 15 \mathrm{~d} / 2$ & GP & $\sqrt{ }$ & $\sqrt{ }$ & $\sqrt{ }$ \\
\hline Sun, G.et.al2008 [19] & $33 / 30$ & $54 / 9$ & $34-73$ & $100 \mathrm{ml} / 14 \mathrm{~d} / 2$ & GP & $\sqrt{ }$ & - & $\sqrt{ }$ \\
\hline Yang, Q, et.al 2008 [20] & $30 / 27$ & $39 / 18$ & $34-82$ & $80 \mathrm{ml} / 8 \mathrm{~d} / 2$ & GP & $\sqrt{ }$ & $\sqrt{ }$ & - \\
\hline Zhao, H.et.al2008 [21] & $30 / 20$ & $31 / 19$ & $29-73$ & $30 \mathrm{ml} / 21 \mathrm{~d} / 3$ & GP & $\sqrt{ }$ & $\sqrt{ }$ & - \\
\hline Lv, D, et.al2009 [22] & $30 / 30$ & $42 / 18$ & $45-70$ & $80 \mathrm{ml} / 10 \mathrm{~d} / 2$ & GP & $\sqrt{ }$ & $\sqrt{ }$ & $\sqrt{ }$ \\
\hline Song, Z, et.al2009 [23] & $30 / 30$ & $36 / 24$ & $53-76$ & $50 \mathrm{ml} / 14 \mathrm{~d} / 2$ & GP & $\sqrt{ }$ & $\sqrt{ }$ & $\sqrt{ }$ \\
\hline Wang, Y2009 [24] & $32 / 27$ & $48 / 11$ & - & $-1-10 \mathrm{~d} / 2$ & GP & $\sqrt{ }$ & - & $\sqrt{ }$ \\
\hline Wen, K, et.al 2009 [25] & $38 / 38$ & $52 / 24$ & $32-77$ & $50 \mathrm{ml} / 8-10 \mathrm{~d} / 2$ & GP & $\sqrt{ }$ & $\sqrt{ }$ & $\sqrt{ }$ \\
\hline Zhang, L2009 [14] & $32 / 31$ & $44 / 19$ & $31-79$ & $80 \mathrm{ml} / 14 \mathrm{~d} / 2$ & GP & $\sqrt{ }$ & $\sqrt{ }$ & $\sqrt{ }$ \\
\hline Hong, Y, et.al 2010 [26] & $90 / 70$ & $82 / 78$ & $38-70$ & $60 \mathrm{ml} / 14 \mathrm{~d} / 2$ & GP & $\sqrt{ }$ & $\sqrt{ }$ & $\sqrt{ }$ \\
\hline Hou, A, et.al 2010 [27] & $40 / 38$ & $49 / 29$ & $32-79$ & $50 \mathrm{ml}, 14 \mathrm{~d}, 2$ & GP & $\sqrt{ }$ & $\sqrt{ }$ & $\sqrt{ }$ \\
\hline Li, Z, et.al 2010 [28] & $36 / 36$ & $39 / 33$ & $29-75$ & $50-100 \mathrm{ml} / 15 \mathrm{~d} / 2$ & GP & $\sqrt{ }$ & $\sqrt{ }$ & $\sqrt{ }$ \\
\hline Liu, Y, et.al 2010 [29] & $32 / 32$ & $37 / 27$ & $45-75$ & $50 \mathrm{ml} / 14 \mathrm{~d} / 4$ & GP & $\sqrt{ }$ & - & $\sqrt{ }$ \\
\hline Shi, X, et.al 2010 [30] & $28 / 28$ & $47 / 9$ & $48-72$ & $50 \mathrm{ml} / 14 \mathrm{~d} / 2$ & GP & $\sqrt{ }$ & $\sqrt{ }$ & $\sqrt{ }$ \\
\hline Ding, P, et.al 2011 [15] & $18 / 22$ & $27 / 13$ & - & $50 \mathrm{ml} / 10 \mathrm{~d} / 2$ & GP & $\sqrt{ }$ & - & - \\
\hline Fan, S, et.al 2011 [31] & $41 / 38$ & $54 / 25$ & $39-73$ & $50 \mathrm{ml} / 21 \mathrm{~d} / 2-4$ & GP & $\sqrt{ }$ & $\sqrt{ }$ & - \\
\hline He, W, et.al 2011 [32] & $29 / 23$ & $29 / 23$ & $21-74$ & $50-100 \mathrm{ml} / 15 \mathrm{~d} / 2-3$ & GP & $\sqrt{ }$ & $\sqrt{ }$ & $\sqrt{ }$ \\
\hline Jiang, S, et.al 2011 [33] & $32 / 30$ & $39 / 23$ & $60-75$ & $100 \mathrm{ml} / 14 / 2$ & GP & $\sqrt{ }$ & - & - \\
\hline Lu, Z, et.al 2011v [34] & $34 / 34$ & $39 / 29$ & $40-76$ & $100 \mathrm{ml} / 14 \mathrm{~d} / 2$ & GP & $\sqrt{ }$ & - & $\sqrt{ }$ \\
\hline Wu, Q, et.a'2011 [35] & $30 / 30$ & $41 / 19$ & $45-77$ & $100 \mathrm{ml} / 16 \mathrm{~d} / 2$ & GP & $\sqrt{ }$ & - & - \\
\hline Fu, L, et.al2012 [36] & $35 / 35$ & - & $61-84$ & $50 \mathrm{ml} / 14 \mathrm{~d} / 2$ & GP & $\sqrt{ }$ & - & - \\
\hline Pei, W2012 [37] & $40 / 40$ & $47 / 33$ & $39-72$ & $50 \mathrm{ml} / 8 \mathrm{~d} / 2$ & GP & $\sqrt{ }$ & - & - \\
\hline Sun, J, et.al2012 [38] & $34 / 34$ & $42 / 26$ & $60-86$ & $50 \mathrm{ml} / 10 \mathrm{~d} / 2$ & GP & $\sqrt{ }$ & $\sqrt{ }$ & $\sqrt{ }$ \\
\hline Wang, J, et.al2012 [39] & $25 / 24$ & $35 / 14$ & - & $60 \mathrm{ml} / 14 \mathrm{~d} / 2$ & GP & $\sqrt{ }$ & - & $\sqrt{ }$ \\
\hline Wang, Y, et.al2012 [40] & $36 / 36$ & $46 / 26$ & $32-74$ & $80 \mathrm{ml} / 10 \mathrm{~d} / 2$ & GP & $\sqrt{ }$ & $\sqrt{ }$ & $\sqrt{ }$ \\
\hline $\mathrm{Xu}, \mathrm{Y}$, et.al2012 [41] & $33 / 33$ & $36 / 30$ & - & $80 \mathrm{mg} / 10 \mathrm{~d} / 4$ & GP & $\sqrt{ }$ & - & $\sqrt{ }$ \\
\hline Zhang, Y2012 [42] & $41 / 42$ & $63 / 20$ & - & $60 \mathrm{ml} / 14 \mathrm{~d} / 3$ & GP & $\sqrt{ }$ & - & $\sqrt{ }$ \\
\hline Cai, H, et.al2013 [43] & $19 / 19$ & $21 / 17$ & $36-68$ & $50-100 \mathrm{ml} / 15 \mathrm{~d} / 2$ & GP & - & - & $\sqrt{ }$ \\
\hline Ju, S, et.al2013 [44] & $34 / 34$ & $36 / 32$ & $61-81$ & $50 \mathrm{ml} / 14 \mathrm{~d} / 2$ & GP & $\sqrt{ }$ & $\sqrt{ }$ & $\sqrt{ }$ \\
\hline Lai, L2013 [45] & $70 / 70$ & $73 / 67$ & $45-79$ & $50 \mathrm{ml} / 14 \mathrm{~d} / 2$ & GP & $\sqrt{ }$ & $\sqrt{ }$ & $\sqrt{ }$ \\
\hline $\mathrm{Xu}, \mathrm{H}$, et.al2013 [46] & $38 / 42$ & $55 / 25$ & $39-81$ & $50 \mathrm{ml} / 14 \mathrm{~d} / 3$ & GP & $\sqrt{ }$ & $\sqrt{ }$ & $\sqrt{ }$ \\
\hline Li, J, et.al2014 [47] & $27 / 27$ & $32 / 22$ & $34-68$ & $50 \mathrm{ml} / 8-10 \mathrm{~d} / 4$ & GP & $\sqrt{ }$ & - & $\sqrt{ }$ \\
\hline Liu, Y, et.al2014 [16] & $43 / 43$ & $53 / 33$ & $39-73$ & $50 \mathrm{ml} / 8-10 \mathrm{~d} / 2$ & GP & $\sqrt{ }$ & - & $\sqrt{ }$ \\
\hline Liu, Z, et.al2014 [48] & $24 / 24$ & $30 / 18$ & $35-80$ & $60 \mathrm{ml} / 21 \mathrm{~d} / 2$ & GP & - & $\sqrt{ }$ & - \\
\hline Wen, H2014 [49] & $45 / 45$ & $64 / 26$ & $61-81$ & $50 \mathrm{ml} / 21 \mathrm{~d} / 2$ & GP & $\sqrt{ }$ & $\sqrt{ }$ & $\sqrt{ }$ \\
\hline
\end{tabular}

Note: Patients: Non-small cell lung cancer (NSCLC); E: Experimental group(Aidi injection plus GP); C: Control group(GP); M: male, F: female; AD: Aidi injection; D/T/C: Dose/times/Cycles; Outcome: O1:Clinical efficacy included ORR and DCR; O2: quality of life (QOL); O3: Acute/subacute toxicity included hematotoxicity, liver injury, renal injury, nausea and vomiting and neurotoxicity. 
all the included studies were described as blinding to patients and doctor. Therefore, it indicated that there were selective bias and implementation bias. All data were complete and selective report did not appear in all of the studies. Other bias was not clear. Characteristics and quality of all included studies are presented in Figure 2.

\section{Clinical efficacy}

In 36 RCTs, 34 trials with 2496 cases were included (Figure 3). There was homogeneity between studies according to the heterogeneity test $\left(\mathrm{Chi}^{2}=17.77\right.$, $\mathrm{P}=0.99, \mathrm{I}^{2}=0 \%$ ). Meta-analysis showed that the ORR was statistically different between the two groups [1.28 (1.17, 1.39), $\mathrm{P}<0.00001)$ ] by fixed-effects model.

Thirty-two trials with 2406 cases were included (Figure 4). There was homogeneity between studies $\left(\mathrm{Chi}^{2}=22.98, \mathrm{P}=0.85, \mathrm{I}^{2}=0 \%\right)$. Meta-analysis showed that the DCR was statistically different between the two groups $[1.11(1.07,1.15), \mathrm{P}<0.00001)$ by fixed-effects model. To compare with chemotherapy alone, all results showed that Aidi injection plus GP could significantly improve the ORR and DCR of patients with NSCLC.

\section{QOL evaluation}

In 36 RCTs, 22 trials with 1702 cases were included (Figure 5). There was homogeneity between studies $\left(\mathrm{Chi}^{2}=20.31, \mathrm{P}=0.50, \mathrm{I}^{2}=0 \%\right)$. Meta-analysis showed that the QOL was statistically different between the two groups [1.81 (1.61, 2.03), $\mathrm{P}<0.00001]$ by fixed-effects model. To compare with chemotherapy alone, result showed that Aidi injection plus GP could significantly improve the QOL of patients with NSCLC.

\section{Acute/subacute toxicity}

\section{Hematotoxicity}

In 36 RCTs, 11 trials with 757 cases were included (Table 2, Figure 6 and Supplementary Figure S1). There was homogeneity between studies $\left(\mathrm{Chi}^{2}=9.35, \mathrm{P}=0.50, \mathrm{I}^{2}\right.$

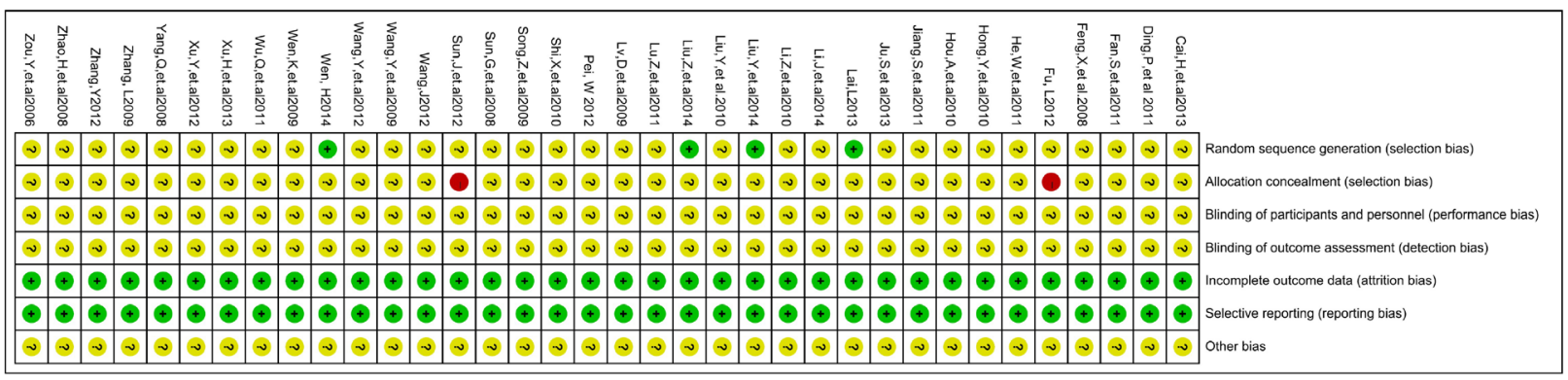

Risk of bias summary: review authors' judgments about each risk of bias item for each included study.

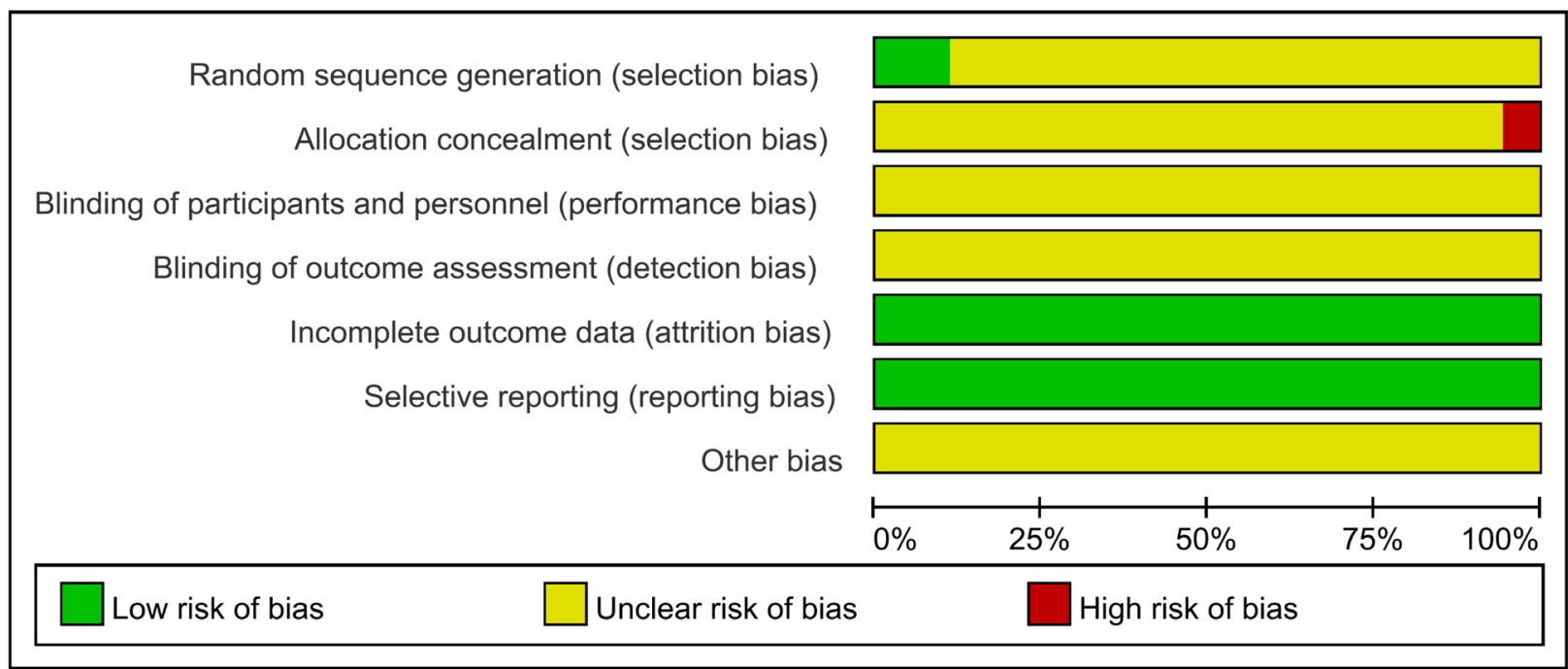

\section{Risk of bias graph: review authors' judgements about each risk of bias item presented as percentages across all included studies.}

Figure 2: Risk of methodological bias of the included studies. 
$=0 \%$ ). Meta-analysis showed that the risk difference(RD) of myelosuppression was statistically different between the two groups $[-0.23(-0.29,-0.17), \mathrm{P}<0.05]$ by fixed-effects model.

In $36 \mathrm{RCTs}$, 13 trials with 1060 cases were included (Table 2, Figure 6 and Supplementary Figure S2). There was homogeneity between studies $\left(\mathrm{Chi}^{2}=23.41, \mathrm{P}=0.02, \mathrm{I}^{2}=49 \%\right)$. Meta-analysis showed that the neutropenia was statistically different between the two groups $[-0.17(-0.22,-0.11), \mathrm{P}<0.05]$ by fixedeffects model.

In 36 RCTs, 11 trials with 924 cases were included (Table 2, Figure 6 and Supplementary Figure S3). There was homogeneity between studies $\left(\mathrm{Chi}^{2}=12.05, \mathrm{P}=0.28\right)$, $\mathrm{I}^{2}=17 \%$ ). Meta-analysis showed that the thrombocytopenia was statistically different between the two groups [-0.13(-0.18, -0.08), $\mathrm{P}<0.05]$ by fixed-effects model. To compare with chemotherapy alone, results showed that Aidi injection plus GP could significantly reduce myelosuppression, neutropenia and thrombocytopenia of patients with NSCLC.

\section{Liver and renal injury}

In 36 RCTs, 7 trials with 567 cases were included (Table 2, Figure 6 and Supplementary Figure S4). There was homogeneity between studies $\left(\mathrm{Chi}^{2}=2.21, \mathrm{P}=0.90, \mathrm{I}^{2}\right.$ $=0 \%$ ). Meta-analysis showed that the liver injury was no statistically different between the two groups [-0.04(-0.10, $0.02), \mathrm{P}=0.16$ ] by fixed-effects model.

In 36 RCTs, 5 trials with 436 cases were included (Table 2, Figure 6 and Supplementary Figure S5). There was homogeneity between studies $\left(\mathrm{Chi}^{2}=0.38, \mathrm{P}=0.98\right.$, $\mathrm{I}^{2}=0 \%$ ). Meta-analysis showed that the renal injury was no statistically different between the two groups [-0.04($0.10,0.02), \mathrm{P}=0.18]$ by fixed-effects model. To compare with chemotherapy alone, none of the results supported that Aidi injection plus GP could reduce the liver and renal injury of patients with NSCLC.

\section{Other toxicity}

In 36 RCTs, 2 trials with 124 cases were included (Table 2, Figure 6 and Supplementary Figure S2). There

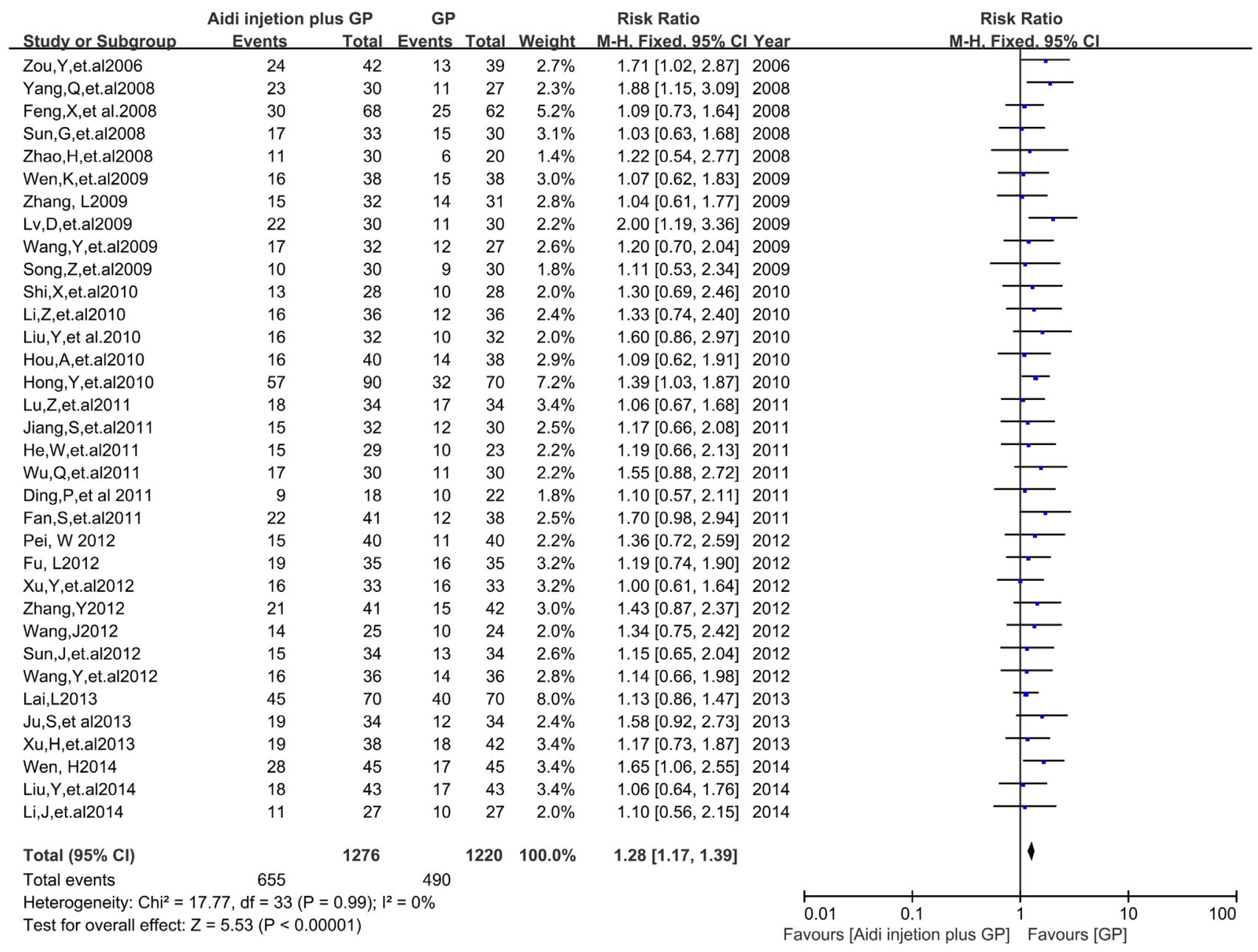

Figure 3: The analysis of ORR between two groups. 
was homogeneity between studies $\left(\mathrm{Chi}^{2}=1.26, \mathrm{P}=0.26\right.$, $\mathrm{I}^{2}=21 \%$ ). Meta-analysis showed that the neurotoxicity was no statistically different between the two groups [-0.06($0.17,0.05), \mathrm{P}=0.25]$ by fixed-effects model.

In 36 RCTs, 15 trials with 1137 cases were included (Table 2, Figure 6 and Supplementary Figure S7). There was homogeneity between studies $\left(\mathrm{Chi}^{2}=14.21, \mathrm{P}=0.43\right.$, $\mathrm{I}^{2}=1 \%$ ). Meta-analysis showed that the nausea and vomitting was statistically different between the two groups $[-0.15(-0.21,-0.10), \mathrm{p}<0.05]$ by fixed-effects model. To compare with chemotherapy alone, all results showed that Aidi injection plus GP could significantly reduce the nausea and vomiting of patients with NSCLC, not the neurotoxicity.

\section{Publication bias and sensitivity analysis}

\section{Publication bias analysis}

The funnel plots were symmetric in the studies about ORR, QOL, myelosuppression and nausea and vomiting (Figure 7A, 7C, 7D and 7G). This indicated that there was no publication bias in these studies which objectively reported the results. The funnel plots were significantly asymmetric in the studies about the DCR, neutropenia, thrombocytopenia (Figure 7B, 7E and 7F). Results showed that all points were asymmetric and some points were distributed outside of the funnel. This indicated that there was publication bias in the included-studies. The DCR [44] was underestimated and the neutropenia [18] and thrombocytopenia [24] were overestimated. All of the above facts were beneficial to the conclusion. Therefore, we didn't implement meta-analysis by excluding the over- or underestimated studies. In summary, all of the results had good objectivity.

\section{Sensitivity analysis}

There was good homogeneity between studies in all meta-analysis. The methodological quality and sample size had good consistency between all included-studies. Therefore, the sensitivity was not evaluated through deleting the high weight or poor studies. In summary, the stability was good in this meta-analysis.

\section{DISCUSSION}

In this study, 36 RCTs were included. There were 2582 NSCLC (III-IV) patients including 1606 male

\begin{tabular}{|c|c|c|c|c|c|}
\hline \multirow[b]{2}{*}{ Study or Subgroup } & \multicolumn{2}{|c|}{ Aidi injetion plus GP } & \multicolumn{2}{|l|}{ GP } & \multirow[b]{2}{*}{ Weight } \\
\hline & Events & Total & Events & Total & \\
\hline Zou,Y,et.al2006 & 35 & 42 & 25 & 39 & $2.8 \%$ \\
\hline Sun,G,et.al2008 & 31 & 33 & 27 & 30 & $3.0 \%$ \\
\hline Yang,Q,et.al2008 & 29 & 30 & 23 & 27 & $2.6 \%$ \\
\hline Feng, $X$,et al.2008 & 62 & 68 & 56 & 62 & $6.3 \%$ \\
\hline Wen,K,et.al2009 & 32 & 38 & 32 & 38 & $3.4 \%$ \\
\hline Lv,D,et.al2009 & 28 & 30 & 23 & 30 & $2.5 \%$ \\
\hline Song,Z,et.al2009 & 27 & 30 & 25 & 30 & $2.7 \%$ \\
\hline Zhang, L2009 & 27 & 32 & 23 & 31 & $2.5 \%$ \\
\hline Wang,Y,et.al2009 & 29 & 32 & 21 & 27 & $2.4 \%$ \\
\hline Liu,Y,et al.2010 & 25 & 32 & 22 & 32 & $2.4 \%$ \\
\hline Li,Z,et.al2010 & 18 & 36 & 21 & 36 & $2.3 \%$ \\
\hline Shi,X,et.al2010 & 27 & 28 & 25 & 28 & $2.7 \%$ \\
\hline Hou,A,et.al2010 & 37 & 40 & 29 & 38 & $3.2 \%$ \\
\hline Hong,Y,et.al2010 & 78 & 90 & 50 & 70 & $6.0 \%$ \\
\hline Fan,S,et.al2011 & 35 & 41 & 29 & 38 & $3.2 \%$ \\
\hline Wu,Q,et.al2011 & 28 & 30 & 26 & 30 & $2.8 \%$ \\
\hline Lu,Z,et.al2011 & 30 & 34 & 28 & 34 & $3.0 \%$ \\
\hline He,W,et.al2011 & 26 & 29 & 19 & 23 & $2.3 \%$ \\
\hline Jiang,S,et.al2011 & 29 & 32 & 25 & 30 & $2.8 \%$ \\
\hline Fu, L2012 & 32 & 35 & 28 & 35 & $3.0 \%$ \\
\hline Zhang,Y2012 & 34 & 41 & 32 & 42 & $3.4 \%$ \\
\hline Xu,Y,et.al2012 & 30 & 33 & 26 & 33 & $2.8 \%$ \\
\hline Pei, W 2012 & 35 & 40 & 27 & 40 & $2.9 \%$ \\
\hline Wang,Y,et.al2012 & 28 & 36 & 20 & 36 & $2.1 \%$ \\
\hline Wang,J2012 & 20 & 25 & 16 & 24 & $1.8 \%$ \\
\hline Sun,J,et.al2012 & 25 & 34 & 25 & 34 & $2.7 \%$ \\
\hline Ju,S,et al2013 & 29 & 34 & 32 & 34 & $3.4 \%$ \\
\hline Lai,L2013 & 63 & 70 & 60 & 70 & $6.4 \%$ \\
\hline Xu,H,et.al2013 & 33 & 38 & 34 & 42 & $3.5 \%$ \\
\hline Wen, H2014 & 43 & 45 & 36 & 45 & $3.9 \%$ \\
\hline Liu,Y,et.al2014 & 35 & 43 & 33 & 43 & $3.5 \%$ \\
\hline Li,J,et.al2014 & 19 & 27 & 16 & 27 & $1.7 \%$ \\
\hline Total $(95 \% \mathrm{Cl})$ & & 1228 & & 1178 & $100.0 \%$ \\
\hline Total events & 1059 & & 914 & & \\
\hline $\begin{array}{l}\text { Heterogeneity: } \mathrm{Ch}^{2}= \\
\text { Test for overall effect }\end{array}$ & $\begin{array}{l}2.98, \mathrm{df}=31 \\
=5.51(\mathrm{P}<\end{array}$ & $\begin{array}{l}0.85) ; I^{2} \\
01)\end{array}$ & $=0 \%$ & & \\
\hline
\end{tabular}

Risk Ratio . Fixed, 95\% Cl Year

$1.30[0.99,1.70] 2006$

$1.04[0.90,1.21] 2008$

$1.13[0.96,1.35] 2008$

$1.01[0.90,1.13] 2008$

$1.00[0.82,1.21] 2009$

$1.22[0.98,1.52] 2009$

$1.08[0.88,1.32] 2009$

$1.14[0.88,1.47] 2009$

$1.17[0.93,1.47] 2009$

$1.14[0.84,1.53] 2010$

$0.86[0.56,1.31] 2010$

$1.08[0.93,1.25] 2010$

$1.21[0.99,1.48] 2010$

$1.21[1.02,1.44] 2010$

$1.12[0.90,1.39] 2011$

$1.08[0.91,1.28] 2011$

$1.07[0.88,1.31] 2011$

$1.09[0.87,1.36] 2011$

$1.09[0.89,1.32] 2011$

$1.14[0.94,1.39] 2012$

$1.09[0.87,1.35] 2012$

$1.15[0.94,1.42] 2012$

$1.30[1.01,1.66] 2012$

$1.40[1.00,1.97] 2012$

$1.20[0.85,1.69] 2012$

$1.00[0.75,1.33] 2012$

$0.91[0.77,1.07] 2013$

$1.05[0.93,1.19] 2013$

$1.07[0.89,1.30] 2013$

$1.19[1.02,1.40] 2014$

$1.06[0.85,1.32] 2014$

$1.19[0.80,1.77] 2014$

$1.11[1.07,1.15]$ M-H. Fixed. $95 \% \mathrm{Cl}$

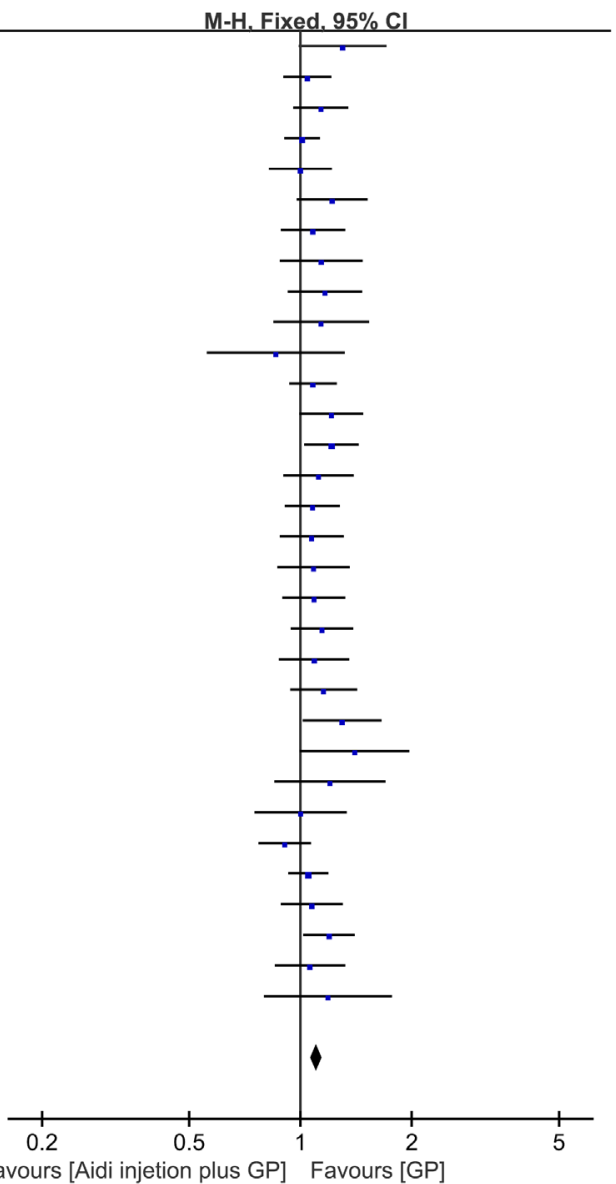

Figure 4: The analysis of DCR between two groups. 
and 906 female patients between 21 and 86 years of age. The dosage of Aidi injection was $50-100 \mathrm{ml} /$ day and treatment time was 2-3 weeks and 2-3 cycles by intravenous injection. According to the WHO guidelines, meta-analysis showed that Aidi injection plus GP could significantly improve the ORR, DCR and QOL of patients with NSCLC. Thirty-six RCTs with 2036 NSCLC patients were included, which ensured sufficient sample size for meta-analysis. The DCR were underestimated which was beneficial to the conclusion. The methodological quality and sample size had good consistency between all included-studies. In summary, all results have good objectivity and stability. Similar meta-analysis [50]showed that Aidi injection plus paclitaxel and cisplatin could significantly improve the clinical efficacy of patients with NSCLC. Cantharidin and Astragalus, Eleutherococcus senticosus and Ginseng are important components of Aidi injection. Animal studies [51] also showed that cantharidin plus chemotherapy had obvious inhibitive effects on the growth of Lewis lung cancer. In-vitro studies [52-53] showed that cantharidin could induce the apoptosis and inhibit the proliferation, migration and invasion of A549 human lung cancer cells. Wu.S2013, et.al [54-56] reported that Aidi injection with chemotherapy could significantly improve the percentage of $\mathrm{CD}^{+} \mathrm{T}$ cells, $\mathrm{CD}^{+} \mathrm{T}$ cells, $\mathrm{CD}^{+} \mathrm{T}$ cells and NK cells and the $\mathrm{CD} 4^{+} / \mathrm{CD}^{+} \mathrm{T}$ cells ratio in peripheral blood, and improve tumor immunity of patient with NSCLC. Many studies [57-62] also showed that Astragalus, senticosus Eleutherococcus, and
Ginseng had anti-tumor activity and immune regulation functions. So we believe that Aidi injection plus GP can significantly increase the clinical efficacy and improve the QOL of patients with NSCLC through inducing the cancer cell apoptosis and up-regulating tumor immunity. These studies indirectly reveal that Aidi injection has synergistic efficacy to GP in NSCLC.

\section{Acute/subacute toxicity}

In 27 RCTs, the hematotoxicity, liver injury, renal injury, neurotoxicity and nausea/vomiting were reported according to the WHO standards [63]. Meta-analysis showed that Aidi injection could significantly reduce the incidence rate of myelosuppression, neutropenia, thrombocytopenia neurotoxicity and nausea/vomiting, but not of the liver and renal injury. Twenty-seven RCTs with 2036 NSCLC patients were included, which ensured sufficient sample size for meta-analysis. But there were smaller sample in the meta-analysis of liver injury, renal injury and neurotoxicity. This might lead to insufficient assessment to them. The neutropenia [18] and thrombocytopenia [24] were overestimated which were beneficial to the conclusion. The methodological quality and sample size had good consistency between all includedstudies. Overall, all results have good objectivity and stability. Similar meta-analysis [64-65] showed that Aidi injection could decrease the toxicity induced by navelbine and cisplatin (NP) or paclitaxel and cisplatin(TP) in NSCLC.

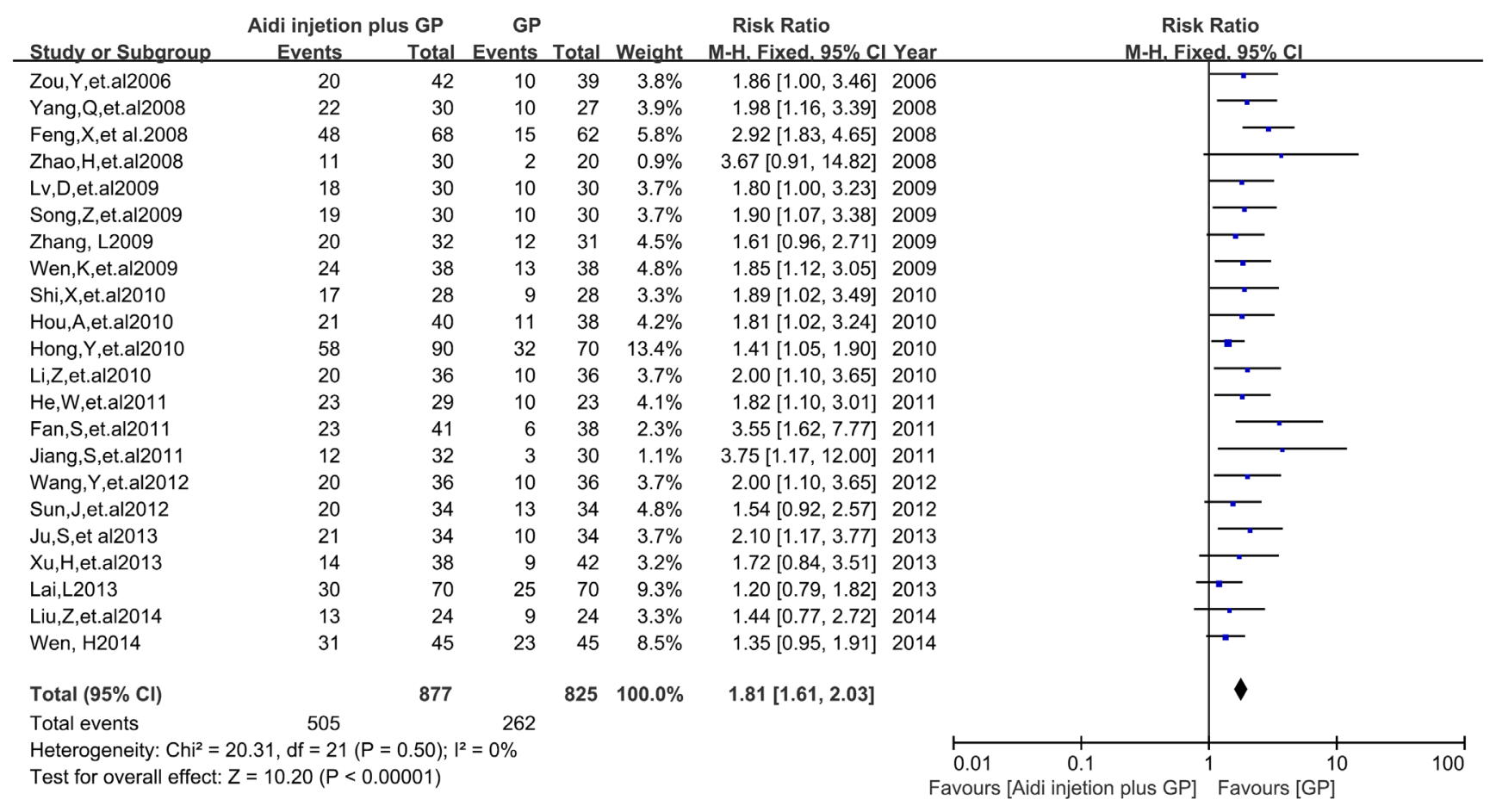

Figure 5: The analysis of QOL between two groups. 
Table 2: Meta analysis results of toxicity between two groups

\begin{tabular}{lcccccccc}
\hline Toxicity & Study & E & C & I2 & $\begin{array}{c}\text { Effect Estimate } \\
\text { RD(95\%(I) }\end{array}$ & P & SM & PB \\
\hline Myelosuppression & 11 & $155 / 383$ & $237 / 374$ & $0 \%$ & $-0.23(-0.29,-0.17)$ & $<0.05$ & FEM & no \\
Neutropenia & 13 & $279 / 544$ & $351 / 516$ & $49 \%$ & $-0.17(-0.22,-0.11)$ & $<0.05$ & FEM & yes \\
Thrombocytopenia & 11 & $165 / 476$ & $215 / 448$ & $17 \%$ & $-0.13(-0.18,-0.08)$ & $<0.05$ & FEM & yes \\
Liver injury & 7 & $38 / 296$ & $47 / 271$ & $0 \%$ & $-0.04(-0.10,0.02)$ & $=0.16$ & FEM & unclear \\
Renal injury & 5 & $18 / 228$ & $25 / 208$ & $0 \%$ & $-0.04(-0.10,0.02)$ & $=0.18$ & FEM & unclear \\
Neurotoxicity & 2 & $5 / 62$ & $9 / 62$ & $21 \%$ & $-0.06(-0.17,0.05)$ & $=0.25$ & FEM & unclear \\
Nausea/vomiting & 15 & $237 / 587$ & $309 / 550$ & $1 \%$ & $-0.15(-0.21,-0.10)$ & $<0.05$ & FEM & no \\
\hline
\end{tabular}

Note: E: Experimental group (events/total); C: Control group (events/total); RD: Risk Difference; CI: Confidence interval; SM: Statistical method; FEM: Fixed-effects model; PB: Publication bias; Forest of all results are in Appendix(Supplementary Figures S1-S7).

Most studies showed that Astragalus, Eleutherococcus senticosus, and Ginseng might reduce the chemotherapy related toxicity through promoting hematopoiesis [66-67] and relieving oxidative stress [68-71]. These studies provide indirect evidence for the above conclusions. In summary, Aidi injection can reduce myelosuppression, neutropenia, thrombocytopenia neurotoxicity and nausea/vomiting, but not the liver and renal injury. These indirectly reveal that Aidi injection can attenuate the acute/subacute toxicity of GP chemotherapy in NSCLC.

\section{Limitations of this study}

There were some limitations in this study. Firstly, Chinese and English databases were retrieved, but not Japanese and Korean databases, all studies were published in China. These could lead to ethnical bias. Secondly, in 36 trials, only 4 trials described the random allocation method. The random allocation concealment and binding to patients and doctors were not described in all of the included-studies. These indicated that there were selective bias and implementation bias and therefore led to the overestimation of the clinical efficacy and attenuation of the treatment group. Thirdly, long term efficacy has not been evaluated and there were smaller sample in the meta-analysis of liver injury, renal injury and neurotoxicity. All of these might lead to an inadequate assessment of the clinical efficacy and attenuation. All together, the quality of the included studies is inadequate and the results need to be further confirmed by standardized studies including RCT or real-world studies.

\begin{tabular}{|c|c|c|c|c|c|}
\hline Toxicity & Studies & $\begin{array}{l}\text { Experimental group } \\
\text { (events/total) }\end{array}$ & $\begin{array}{l}\text { Control group } \\
\text { (events/total) }\end{array}$ & Risk Difference $(95 \% \mathrm{CI})$ & Effect Estimate \\
\hline Myelosuppression & 11 & $155 / 383$ & $237 / 374$ & & $-0.23(-0.29,-0.17)$ \\
\hline Neutropenia & 13 & $279 / 544$ & $351 / 516$ & & $-0.17(-0.22,-0.11)$ \\
\hline Thrombocytopenia & 11 & $165 / 476$ & $215 / 448$ & & $-0.13(-0.18,-0.08)$ \\
\hline Liver injury & 7 & $38 / 296$ & $47 / 271$ & $\begin{array}{ll}-1 \\
\end{array}$ & $-0.04(-0.10,0.02)$ \\
\hline Renal injury & 5 & $18 / 228$ & $25 / 208$ & & $-0.04\langle-0.10,0.02\}$ \\
\hline Neurotoxicity & 2 & $5 / 62$ & $9 / 62$ & & $-0.06(-0.17,0.05)$ \\
\hline Nausea and vomiting & 15 & $237 / 587$ & $309 / 550$ & & $-0.15(-0.21,-0.10)$ \\
\hline
\end{tabular}

Figure 6: Meta analysis results of toxicity between two groups. 


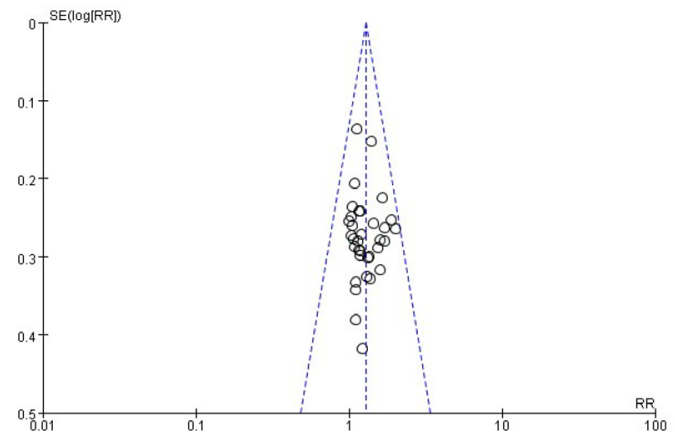

7A. ORR

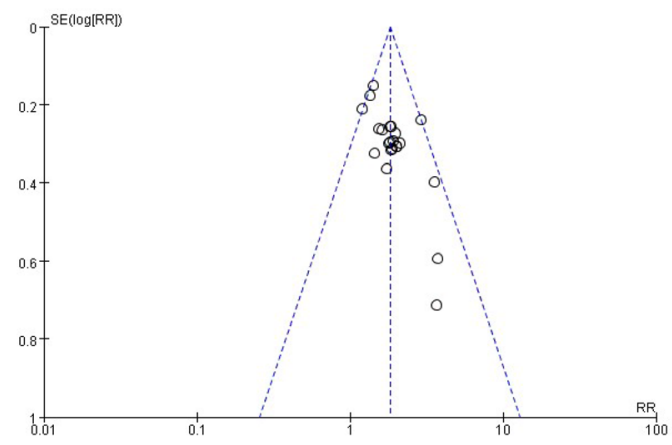

7C.QOL

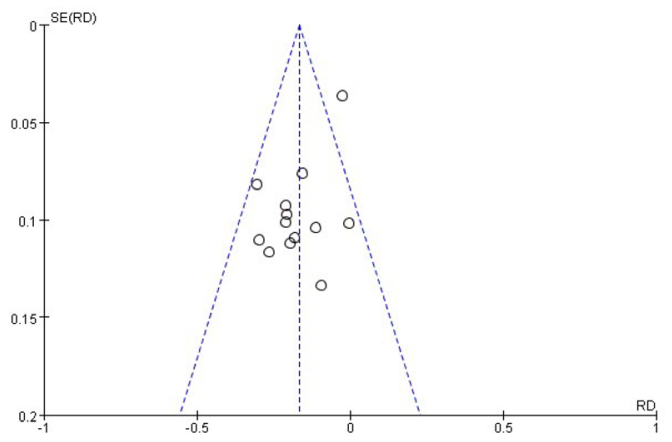

7E. Neutropenia

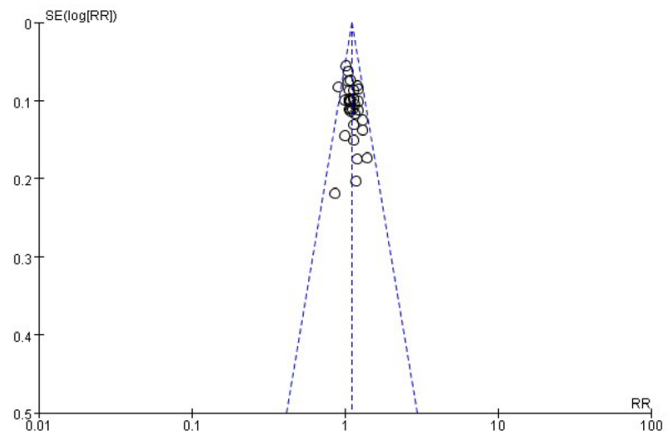

7B. DCR

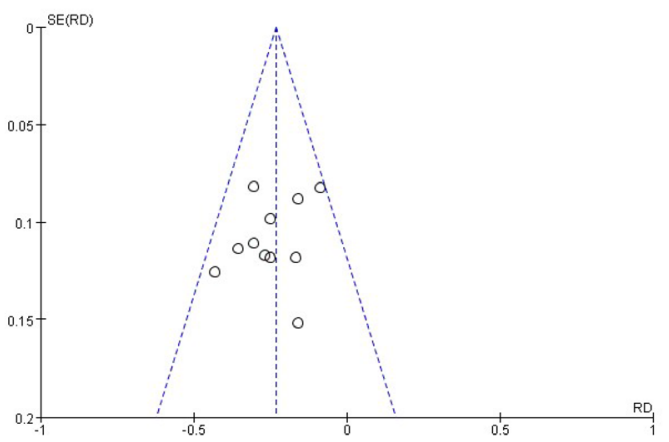

7D. Myelosuppression

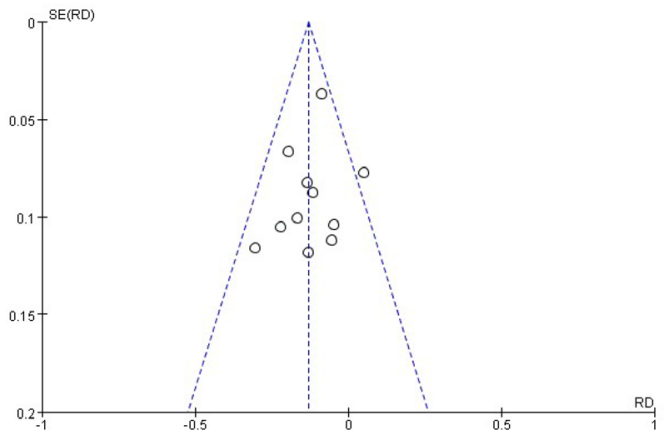

7F. Thrombocytopenia

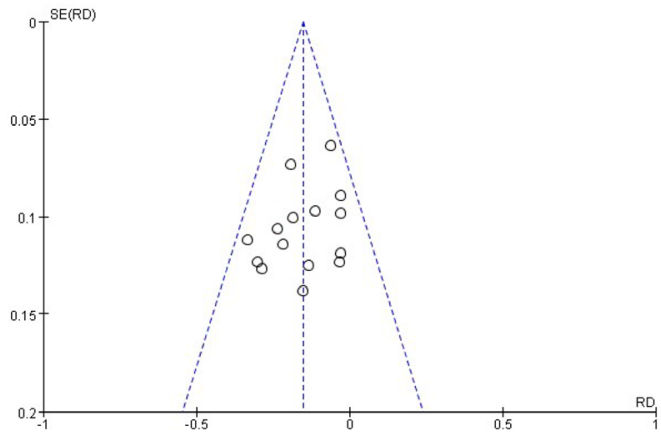

7G. Nausea and vomiting

Figure 7: Publication bias analysis. 


\section{MATERIALS AND METHODS}

This article followed Preferred Reporting Items for Systematic Reviews and Meta-Analyses (PRISMA) guidelines.

\section{Literature search strategy}

Two reviewers (Xuemei Tang and Chengqiong Wang) independently searched articles in electronic databases using the search strategy ("Lung Neoplasms" [Mesh] OR Pulmonary Neoplasms OR Lung Neoplasm OR Pulmonary Neoplasm OR Lung Cancer OR Lung Cancers OR Pulmonary Cancer OR Pulmonary Cancers OR lung carcinoma OR Pulmonary carcinoma OR NSCLC) AND (aidi OR aidi injection). Published studies were retrieved in Medline, Embase, Web of Science, China National Knowledge Infrastructure Database(CNKI), Chinese Scientific Journals Full-Text Database(VIP), Wanfang Database, China Biological Medicine Database (CBM) ( established to June 2015) and Cochrane Central Register of Controlled Trials (CCRCT, Issue 6 of 12, June 2015). Unpublished studies were retrieved in Chinese clinical trial registry (Chi-CTR) and US-clinical trials (established to June 2015). All retrievals were implemented by the Mesh and free word. No language restrictions were placed on the search. Ethical approval was not required, as our study pertains only to the metaanalysis of published or unpublished studies.

\section{Studies inclusion and exclusion criteria}

\section{Inclusion criteria}

Included studies must meet the following criteria: (1) We included all studies with NSCLC (III-IV) in accordance with histopathological and cytological diagnostic criteria and non operative patients. (2) There were randomized controlled trials (RCTs) groups. (3) The experimental group was Aidi injection plus GP and the control group was GP.(4) Subjects previously included in the study did not receive other therapies including other Chinese herbs and intraarterial infusion chemotherapy. (5) Clinical efficacy: According to the World Health Organization (WHO) guidelines [63] for solid tumor responses, indicators were complete response (CR), partial response (PR), no change (NC), progressive disease (PD), objective response rate (ORR) equals $\mathrm{CR}+\mathrm{PR}$ and disease control rate (DCR) equals $\mathrm{CR}+\mathrm{PR}+\mathrm{NC}$. Clinical efficacy was evaluated by objective response rate (ORR) and disease control rate (DCR). Quality of life (QOL): According to karnofsky performance score (KPS) grading system, QOL was improved when KPS increased 10 points after the treatment. Acute/subacute toxicity: According to WHO standards [63], the acute/subacute toxicity was evaluated by hematotoxicity including neutropenia (granulocytes $<2 \times 10^{9} / \mathrm{L}$ ), thrombocytopenia (platelets $<100 \times 10^{9} / \mathrm{L}$ ), and myelosuppression), liver and renal injury, neurotoxicity and nausea and vomiting. (6)Time and settings: no restrictions were set on the duration of follow-ups or types of settings.

\section{Exclusion criteria}

Excluded studies must meet the following criteria: (1) Duplicated articles. (2) Unrelated studies including other themes, and animal and in-vitro studies. (3) Non-randomized controlled studies, (4) Abstracts and reviews without specific data. (5) Studies with inaccurate information or non-usable statistical data.

\section{Study quality evaluation}

We evaluated the quality of all included-studies according to the Cochrane evaluation handbook of RCTs (5.1.0) [72]. The bias parameters were the random sequence generation (selection bias), the allocation concealment (selection bias), the blinding of participants and personnel (performance bias), the blinding of outcome assessment (detection bias), the incomplete outcome data (attrition bias), the selective report (reporting bias), and the other bias. We judged each item on three levels ("Yes" for low bias, "No" for a high risk of bias, and "Unclear"). Then, we assessed the trials and categorized them into three levels: low risk of bias (all the items were categorized "Yes"), high risk of bias (at least one item ranked "No"), and unclear risk of bias (at least one item was "Unclear").

\section{Selection and evaluation of articles}

Two reviewers (Nana $\mathrm{Li}$ and Xuemei Tang) independently selected and evaluated articles according to the above standards. Any disagreements were resolved by discussing between themselves or with Zheng Xiao.

\section{Data extraction and statistical analysis}

Two reviewers (Lianhong Li and Xuemei Tang) independently extracted all data including: (1) Publishing time and country. (2) Study design including the randomization methods, demographic characteristics and blinding implementation. (3) The sample size of experimental and control group. (4) Clinical efficacy including ORR, DCR and QOL and acute or subacute toxicity including hematotoxicity, liver and renal injury, neurotoxicity and nausea and vomiting. Meta-analysis was implemented by two reviewers (Chengqiong Wang and Jing Li) with Review Manager 5.3 (The Cochrane Collaboration, Oxford, UK). The relative risk (RR), Risk difference (RD) and 95\% confidence intervals (CI) were calculated. Statistical heterogeneity of the results across trials was assessed by Chi-square based Q-statistic test and 
the inconsistency was calculated by $\mathrm{I}^{2}$. If the homogeneity $\left(\mathrm{P} \geq 0.1, \mathrm{I}^{2} \leq 50 \%\right.$ ) was not rejected, the fixed-effects model was used to calculate the RR and the $95 \%$ CI. The results were analyzed by random-effects model, if the heterogeneity $\left(P<0.1, I^{2}>50 \%\right)$ was higher and the results of the fixed and random effect model had good consistency. The clinical heterogeneity was handled by strict inclusion and exclusion criteria and subgroups analysis. Statistical heterogeneity was reduced by random effects model if the results of the fixed and random effect model had good consistency. Otherwise, the results were analyzed by descriptive analysis. Publication bias was evaluated through funnel plots if there were more than 10 included studies. The sensitivity was evaluated through deleting the studies with high weight, poor, over- or underestimated results.

\section{CONCLUSIONS}

To compare with GP chemotherapy, Aidi injection plus GP can significantly increase the clinical efficacy and improve the QOL of patients with NSCLC. Aidi injection can reduce the myelosuppression, neutropenia, thrombocytopenia neurotoxicity and nausea/vomiting, but not the liver and renal injury. These indirectly reveal that Aidi injection has attenuation and synergistic efficacy to GP chemotherapy in NSCLC. Its long-term effect is not clear. The quality of the included studies is inadequate. The results need to be confirmed by further large sample RCT or real-world studies with longer follow-ups.

\section{APPENDIX}

Forest plot and Funnel plot of the toxicity between two groups(Supplementary Figures S1-S7).

\section{CONFLICTS OF INTERESTS}

The authors have no conflicts of interest to declare.

\section{FUNDING}

This work was funded by grants from Development fund of evidence based transformation in Affiliated Hospital of Zunyi Medical College (No.2016), Doctoral Fund of Zunyi Medical College (No. F-617) and Planning fund of philosophy and social science in Guizhou (No.14GZYB58) and The Fifth Science and Technology Innovation Team for "Basic and Clinical Studies of Drug-resistant Tuberculosis in Guizhou Province" (No. 2012 4011).

\section{Author's contributions}

Conception and design: Zheng Xiao. Development of methodology: Zheng Xiao and Chengqiong Wang. Literature search: Xuemei Tang and Chengqiong Wang.
Selection and Evaluation of Articles: Nana Li and Xuemei Tang. Data Extraction: Lianhong Li and Xuemei Tang. Statistical Analysis: Chengqiong Wang and Jing Li. Writing, review, and/or revision of the manuscript: All authors. Study supervision: Zheng Xiao. All authors reviewed the PRISMA criteria for authorship and agreed with manuscript results and conclusions.

\section{REFERENCES}

1. Tsao AS, Scagliotti GV, Bunn PA, Jr., Carbone DP, Warren GW, Bai C, de Koning HJ, Yousaf-Khan AU, McWilliams A, Tsao MS, Adusumilli PS, Rami-Porta R, Asamura H, Van Schil PE, Darling GE, Ramalingam SS, et al. Scientific Advances in Lung Cancer 2015. J Thorac Oncol. 2016; 11:613-638.

2. Grilli R, Oxman AD, Julian JA. Chemotherapy for advanced non-small-cell lung cancer: how much benefit is enough? J Clin Oncol. 1993; 11:1866-1872.

3. Hsia TC, Tu CY, Fang HY, Liang JA, Li CC, Chien CR. Cost and effectiveness of image-guided radiotherapy for non-operated localized lung cancer: a population-based propensity score-matched analysis. J Thorac Dis. 2015; 7:1643-1649.

4. Anagnostou VK, Brahmer JR. Cancer immunotherapy: a future paradigm shift in the treatment of non-small cell lung cancer. Clin Cancer Res. 2015; 21:976-984.

5. Janne PA, Paz-Ares L, Oh Y, Eschbach C, Hirsh V, Enas N, Brail L, von Pawel J. Randomized, double-blind, phase II trial comparing gemcitabine-cisplatin plus the LTB4 antagonist LY293111 versus gemcitabine-cisplatin plus placebo in first-line non-small-cell lung cancer. J Thorac Oncol. 2014; 9:126-131.

6. Brodowicz T, Krzakowski M, Zwitter M, Tzekova V, Ramlau R, Ghilezan N, Ciuleanu T, Cucevic B, Gyurkovits K, Ulsperger E, Jassem J, Grgic M, Saip P, Szilasi M, Wiltschke C, Wagnerova M, et al. Cisplatin and gemcitabine first-line chemotherapy followed by maintenance gemcitabine or best supportive care in advanced non-small cell lung cancer: a phase III trial. Lung Cancer. 2006; 52155-163.

7. Reck M, von Pawel J, Zatloukal P, Ramlau R, Gorbounova V, Hirsh V, Leighl N, Mezger J, Archer V, Moore N, Manegold C. Overall survival with cisplatin-gemcitabine and bevacizumab or placebo as first-line therapy for nonsquamous non-small-cell lung cancer: results from a randomised phase III trial (AVAiL). Ann Oncol. 2010; 21:1804-1809.

8. Wachters FM, Van Putten JW, Kramer H, Erjavec Z, Eppinga P, Strijbos JH, de Leede GP, Boezen HM, de Vries EG, Groen HJ. First-line gemcitabine with cisplatin or epirubicin in advanced non-small-cell lung cancer: a phase III trial. Br J Cancer. 2003; 89:1192-1199.

9. Lee NS, Byun JH, Bae SB, Kim CK, Lee KT, Park SK, Won JH, Hong DS, Park HS. Combination of gemcitabine 
and cisplatin as first-line therapy in advanced non-small-cell lung cancer. Cancer Res Treat. 2004; 36:173-177.

10. Hsia TC, Lin JH, Hsu SC, Tang NY, Lu HF, Wu SH, Lin JG, Chung JG. Cantharidin induces DNA damage and inhibits DNA repair-associated protein levels in NCI-H460 human lung cancer cells. Environ Toxicol. 2015; 30:1135-1143.

11. Zhou X, Shi H, Jiang G, Zhou Y, Xu J. Antitumor activities of ginseng polysaccharide in $\mathrm{C} 57 \mathrm{BL} / 6$ mice with Lewis lung carcinoma. Tumour Biol. 2014; 35:12561-12566.

12. Suh SO, Kroh M, Kim NR, Joh YG, Cho MY. Effects of red ginseng upon postoperative immunity and survival in patients with stage III gastric cancer. Am J Chin Med. 2002; 30483-494.

13. Kim HS, Lim JM, Kim JY, Kim Y, Park S, Sohn J. Panaxydol, a component of Panax ginseng, induces apoptosis in cancer cells through EGFR activation and ER stress and inhibits tumor growth in mouse models. Int $\mathrm{J}$ Cancer. 2016; 138:1432-1441.

14. Zhang L. Aidi injection combined with gemcitabine hydrochloride and cisplatin for advanced non small cell lung cancer: A clinical study. Journal of Practical Medicine. 2009; 25:2929-2930.

15. Ding $\mathrm{P}, \mathrm{Ge} \mathrm{H}, \mathrm{Li} \mathrm{M}, \mathrm{Zhu} \mathrm{M}$. Aidi injection combined with gemcitabine hydrochloride and cisplatin for advanced non small cell lung cancer: A clinical study. Journal of Clinical Pulmonary Medicine. 2011; 16:1802-1803.

16. Liu Y, Zhao Y. Aidi injection combined with GP for advanced non-small cell lung cancer: A clinical study. China Practical Journal of Medicine. 2014; 41:67-69.

17. Zou Y, Li J, Luo X. Aidi injection combined with GP chemotherapy for advanced lung cancer: A clinical study. Hubei J Traditional Chinese Medicine. 2006; 28:33-34.

18. Feng X, Li X, Cui E. Aidi injection combined with GP for non small cell lung cancer: A clinical study of 68 cases. Journal of Oncology. 2008; 14:892-893.

19. Sun G, Liu J, Wang T, Zhu J. Aidi injection combined with gemcitabine and cisplatin for advanced non small cell lung cancer: A clinical study of 33 cases. Fujian Medical Journal. 2008; 30:134-134.

20. Yang Q, Chen W, Huang J, Chen X. Aidi injection combined with chemotherapy in the treatment of advanced lung cancer. Guangming J Chinese Medicine. 2008; 23:1760-1761.

21. Zhao H, Zhao Y, Su H, Wang C. Aidi injection combined with gemcitabine hydrochloride and cisplatin for advanced non small cell lung cancer: A clinical study. Chinese J Misdiagnostics. 2008; 8:5873-5874.

22. Lv D, Guo Q, Qiu Y. Aidi injection combined with gemcitabine and cisplatin for advanced non small cell lung cancer: A clinical study of 30 cases. Jiangxi J Traditional Chinese Medicine. 2009; 40:47-48.

23. Song Z, Liu X, Zhang H, Shang Y, Xu Y. Aidi injection combined with gemcitabine hydrochloride and cisplatin for advanced non small cell lung cancer: A clinical study. Medical Research and Education. 2009; 26:36-37.
24. Wang Y. Aidi injection combined with chemotherapy in the treatment of elderly patients with advanced non-small cell lung cancer: A clinical study. Chinese Primary Health Care. 2009; 23:101-102.

25. Wen K, Li J, Peng D. Aidi injection combined with gemcitabine hydrochloride and cisplatin for advanced non small cell lung cancer: A clinical study. Chinese J Basic Medicine in Traditional Chinese Medicine. 2009; 15:716-717.

26. Hong Y, Wang J, Jiao Z. Aidi injection combined with gemcitabine hydrochloride and cisplatin for advanced non small cell lung cancer: A clinical study. Chinese J Clinical Oncology and Rehabilitation. 2010; 17:247-249.

27. Hou A, Zhang L. Aidi injection combined with gemcitabine and cisplatin for advanced non small cell lung cancer: A clinical study of 78 cases. World Health Digest. 2010; 07:285-286.

28. Li Z, Liu X, Yuan L. Aidi injection combined with gemcitabine hydrochloride and cisplatin for advanced non small cell lung cancer: A clinical study. Journal Community Medicine. 2010; 08:23-24.

29. Liu Y, Liu Y, Zhang T. Aidi injection combined with chemotherapy for advanced non-small cell lung cancer: A short-term curative effect study. National Medical Frontiers of China. 2010; 05:46-46.

30. Shi X, Yu A, Yang Y, Jin X, Dai L, Zhang T, Wang M, Wang Z, Pan W. Aidi injection combined with chemotherapy for advanced non-small cell lung cancer: A clinical study. Zhejiang J Integrated Traditional Chinese and Western Medicine. 2010; 20:747-748.

31. Fan S, Peng L, Qi X. Aidi injection combined with chemotherapy for advanced non-small cell lung cancer: A clinical study. Zhejiang J Integrated Traditional Chinese and Western Medicine. 2011; 21:232-233.

32. $\mathrm{He} \mathrm{W}, \mathrm{Wu} \mathrm{L}, \mathrm{Yu} \mathrm{C}$, Song Y. Aidi injection combined with gemcitabine hydrochloride and cisplatin for advanced non small cell lung cancer: A clinical study. Journal of Logistics University of Capf. 2011; 20:296-297, 326.

33. Jiang S, Mao X, Hong J. Aidi injection combined with chemotherapy for advanced non small cell lung cancer: A clinical study of 32 cases. Zhejiang J Integrated Traditional Chinese and Western Medicine. 2011; 21:24-26.

34. Lu Z, Xu L, Yu J, Wang D. Aidi injection combined with chemotherapy for advanced non-small cell lung cancer: A clinical study. China Modern Medicine. 2011; 18:72-73.

35. Wu Q, He X. Aidi injection combined with chemotherapy for advanced non-small cell lung cancer: A clinical study. China J Chinese Materia Medica. 2011; 36:3364-3365.

36. Fu L. Aidi injection combined with GP in the treatment of elderly patients with advanced non-small cell lung cancer: A clinical study. Guide of China Medicine. 2012;:466.

37. Pei W. Efficacy of Aidi Injection combined with GP regimen in patients with advanced non-small cell lung cancer and the impact on expression of serum VEGF. China Medical Herald. 2012; 09:99-100. 
38. Sun J, Xu P, Shi D, Cao B. Evaluation on clinical efficacy of Aidi injection combined with GP chemotherapy in treatment of advanced non-small cell lung cancer in elder patients. Journal of Jilin University(Medicine Edition). 2012; 38:151-154.

39. Wang J. Clinical study of Aidi injection combined with GP chemotherapy on treatment of non-small cell lung cancer. Journal of Clinical Pulmonary Medicine. 2012; 17:312-313.

40. Wang Y, Peng L. Clinical study on Aidi injection combined GP for treating advanced non-small cell lung cancer. Chinese Community Doctors. 2012; 14:231-232.

41. Xu Y, Zhang Y, Lu B. Clinical study on Aidi injection combined chemotherapy for treating middle and late stage lung cancer China Pharmaceuticals. 2012; 21:56-57.

42. Zhang Y. Aidi injection combined with GP for non small cell lung cancer: A clinical study. Modern Journal of Integrated Traditional Chinese and Western Medicine. 2012; 21:2095-2096.

43. Cai H, Zou H, Chai Y, Zhu H. Clinical study of Aidi injection and GP chemotherapy to improve the quality of life in patients with non-small cell lung cancer. Medicine and Pharmacy of Yunnan. 2013;365-365.

44. Ju S, Li C, Xu Y. Aidi injection combined with GP in the treatment of elderly patients with advanced non-small cell lung cancer: A clinical study. Strait Pharmaceutical Journal. 2013; 25:206-207.

45. Lai L. Aidi injection combined with GP in the treatment of elderly patients with advanced non-small cell lung cancer: A clinical study. Modern Journal of Integrated Traditional Chinese and Western Medicine. 2013; 7-258.

46. Xu H, Yang T, Zhou M. Clinical evaluation of Aidi injection combined with chemotherapy for advanced non-small cell lung cancer. International Journal of Respiration. 2013; 33:765-767.

47. Li J, Yang G. Clinical evaluation of Aidi injection combined with GP for advanced non-small cell lung cancer. Heilongjiang Medical Journal. 2014; 38:447-448.

48. Liu Z, Zhang C. Aidi injection combined with GP for advanced non-small cell lung cancer:A randomized and paralleled study. Journal of Practical Traditional Chinese Internal Medicine. 2014; 28:65-67.

49. Wen H. Clinical evaluation of TCM combined with Western Medicine for elderly patients with advanced non-small cell lung cancer. Modern Journal of Integrated Traditional Chinese and Western Medicine. 2014; 23:2325-2326.

50. Wang Q, He X, Tian J, Wang X, Ru P, Ruan Z, Yang K. A meta analysis of Aidi Injection plus taxotere and cisplatin in the treatment of non-small cell lung Cancer. Chin J Lung Cancer. 2010; 13:1027-1034.

51. Li XW, Li NL, Zhao LY, Li YQ. Experiment on expression of nm23-1 gene in lung cancer mice affected by cantharidin. Chinese Journal of Clinical Rehabilitation. 2005; 9:96-98.
52. Zhang W, Zhao H, Yan Y, Wang X, Zong Z, Liu Y. Apoptosis induced by cantharidin in human pulmonary carcinoma cells A549 and its molecular mechanisms. Chinese Journal of Oncology. 2005; 27:330-334.

53. Kim YM, Ku MJ, Son YJ, Yun JM, Kim SH, Lee SY. Antimetastatic effect of cantharidin in A549 human lung cancer cells. Arch Pharm Res. 2013; 36:479-484.

54. Jiang S, Mao X, Hong J. Aidi injection combining chemotherapy in the treatment of advanced non-small cell lung cancer: a clinical observation of 32 cases. Zhejiang $\mathbf{J}$ ITCWM. 2011; 21:24-26.

55. Li J, Wang J, Zhu Y, Lu B, Wang K, Wang Z, Wang J. Clinical observation of Aidi injection combined with chemotherapy in treatment of advanced non small cell lung cancer. Hainan Med J. 2014; 25:3444-3447.

56. Wu S, Xu S. Clinical observation on the effect of Aidi injection in the treatment of advanced NSCLC. Chin J Medicinal Guide. 2013; 15:116-117.

57. Cichello SA, Yao Q, Dowell A, Leury B, He XQ. Proliferative and Inhibitory Activity of Siberian ginseng (Eleutherococcus senticosus) Extract on Cancer Cell Lines; A-549, XWLC-05, HCT-116, CNE and Beas-2b. Asian Pac J Cancer Prev. 2015; 16:4781-4786.

58. Wang HC, Tseng YH, Wu HR, Chu FH, Kuo YH, Wang SY. Anti-proliferation effect on human breast cancer cells via inhibition of $\mathrm{pRb}$ phosphorylation by taiwanin $\mathrm{E}$ isolated from Eleutherococcus trifoliatus. Nat Prod Commun. 2014; 9:1303-1306.

59. Chu DT, Lepe-Zuniga J, Wong WL, LaPushin R, Mavligit GM. Fractionated extract of Astragalus membranaceus, a Chinese medicinal herb, potentiates LAK cell cytotoxicity generated by a low dose of recombinant interleukin-2. J Clin Lab Immunol. 1988; 26:183-187.

60. Chu DT, Wong WL, Mavligit GM. Immunotherapy with Chinese medicinal herbs. II. Reversal of cyclophosphamideinduced immune suppression by administration of fractionated Astragalus membranaceus in vivo. J Clin Lab Immunol. 1988; 25:125-129.

61. Kormosh N, Laktionov K, Antoshechkina M. Effect of a combination of extract from several plants on cell-mediated and humoral immunity of patients with advanced ovarian cancer. Phytother Res. 2006; 20:424-425.

62. Shao BM, Xu W, Dai H, Tu P, Li Z, Gao XM. A study on the immune receptors for polysaccharides from the roots of Astragalus membranaceus, a Chinese medicinal herb. Biochem Biophys Res Commun. 2004; 320:1103-1111.

63. Miller AB, Hoogstraten B, Staquet M, Winkler A. Reporting results of cancer treatment. Cancer. 1981; 47:207-214.

64. $\mathrm{Wu} \mathrm{B}, \mathrm{Xu} \mathrm{L}$, Chen M. Aidi injection combined with paclitaxel plus cisplatin for advanced non small cell lung cancer: a meta-analysis. Zhejiang J Integrated Traditional Chinese and Western Medicine. 2009; 19:446-447. 
65. Yang J, Ding M. Eddie combined with gemcitabine and cisplatin for advanced non-Small cell lung cancer:MetaAnalysis. Chinese General Practice. 2012; 15:2794-2798.

66. Miller SC, Ti L, Shan JJ. The sustained influence of short term exposure to a proprietary extract of North American ginseng on the hemopoietic cells of the bone marrow, spleen and blood of adult and juvenile mice. Phytother Res. 2012; 26:675-681.

67. Raghavendran HR, Sathyanath R, Shin J, Kim HK, Han JM, Cho J, Son CG. Panax ginseng modulates cytokines in bone marrow toxicity and myelopoiesis: ginsenoside Rg1 partially supports myelopoiesis. PLoS One. 2012; 7:e33733.

68. Kopalli SR, Cha KM, Jeong MS, Lee SH, Sung JH, Seo SK, Kim SK. Pectinase-treated Panax ginseng ameliorates hydrogen peroxide-induced oxidative stress in GC-2 sperm cells and modulates testicular gene expression in aged rats. J Ginseng Res. 2016; 40:185-195.
69. Lam P, Cheung F, Tan HY, Wang N, Yuen MF, Feng Y. Hepatoprotective Effects of Chinese Medicinal Herbs: A Focus on Anti-Inflammatory and Anti-Oxidative Activities. Int J Mol Sci. 2016; 17.

70. Huang YF, Lu L, Zhu DJ, Wang M, Yin Y, Chen DX, Wei LB. Effects of Astragalus Polysaccharides on Dysfunction of Mitochondrial Dynamics Induced by Oxidative Stress. Oxid Med Cell Longev. 2016; 2016:9573291.

71. Shahzad M, Small DM, Morais C, Wojcikowski K, Shabbir A, Gobe GC. Protection against oxidative stress-induced apoptosis in kidney epithelium by Angelica and Astragalus. J Ethnopharmacol. 2016; 179:412-419.

72. Higgins JPT GS. Cochrane Handbook for Systematic Reviews of Interventions Version 5.1.0. [updated March 2011]. Available at:http://wwwhandbookcochraneorg/. 